\title{
Cognitive deficits following exposure to pneumococcal meningitis: an event-related potential study
}

\author{
Michael Kihara ${ }^{1 *}$, Michelle de Haan ${ }^{2}$, Eugene O Were ${ }^{1,3}$, Harrun H Garrashi ${ }^{1}$, Brian GR Neville ${ }^{4}$ and
} Charles RJC Newton ${ }^{1,4,5}$

\begin{abstract}
Background: Pneumococcal meningitis (PM) is a severe and life-threatening disease that is associated with cognitive impairment including learning difficulties, cognitive slowness, short-term memory deficits and poor academic performance. There are limited data on cognitive outcomes following exposure to PM from Africa mainly due to lack of culturally appropriate tools. We report cognitive processes of exposed children as measured by auditory and visual event-related potentials.
\end{abstract}

Methods: Sixty-five children (32 male, mean 8.4 years, SD 3.0 years) aged between 4-15 years with a history of PM and an age-matched control group of 93 children (46 male; mean 8.4 years, SD 2.7 years) were recruited from a well-demarcated study area in Kilifi. In the present study, both baseline to peak and peak-to-peak amplitude differences are reported.

Results: Children with a history of pneumococcal meningitis had significantly longer auditory P1 and P3a latencies and smaller P1 amplitudes compared to unexposed children. In the visual paradigm, children with PM seemingly lacked a novelty P3a component around $350 \mathrm{~ms}$ where control children had a maximum, and showed a lack of stimulus differentiation at Nc. Further, children with exposure to PM had smaller peak to peak amplitude (N2-P1) compared to unexposed children.

Conclusion: The results suggest that children with a history of PM process novelty differently than do unexposed children, with slower latencies and reduced or absent components. This pattern suggests poorer auditory attention and/or cognitive slowness and poorer visual attention orienting, possibly due to disruption in the functions of the lateral prefrontal and superior temporal cortices. ERPs may be useful for assessment of the development of perceptual-cognitive functions in post brain-injury in African children by providing an alternate way of assessing cognitive development in patient groups for whom more typical standardized neuropsychological assessments are unavailable.

\section{Background}

Pneumococcal meningitis (PM) is an infection of the membranes covering the brain and spinal cord caused by Streptococcus pneumoniae [1]. The case fatality rate for PM in resource-constrained countries varies from $12-50 \%[2,3]$, which is much higher than in developed countries, and much more than other forms of bacterial

\footnotetext{
* Correspondence: mkihara@kilifi.kemri-wellcome.org

${ }^{1}$ The Centre for Geographical Medicine Research (Coast), Kenya Medical Research Institute, Kilifi, Kenya

Full list of author information is available at the end of the article
}

meningitis [2]. Cognitive dysfunction following the infection is reported [4-9] including learning difficulties, cognitive slowness, short-term memory deficits and poor academic performance [10-13].

Methodological limitations contribute to the paucity of data on cognitive outcomes of children following PM in Africa. Neuropsychological assessments are arguably the most important tools [14], but in Africa, lack of standardization, low literacy levels, language and cultural barriers [15,16] limit successful testing [17].

\section{Biomed Central}

(c) 2012 Kihara et al; licensee BioMed Central Ltd. This is an Open Access article distributed under the terms of the Creative Commons Attribution License (http://creativecommons.org/licenses/by/2.0), which permits unrestricted use, distribution, and reproduction in any medium, provided the original work is properly cited. 
Event related potentials (ERPs) are electroencephalographic changes that are time-locked to sensory and cognitive events and represent the neurophysiologic processing of these events [18]. ERPs reflect the activation of neural structures in the sensory cortex, cortical association areas and higher order cognitive areas [19]. They measure basic sensory processing abilities related to cognition and have been used successfully in studying the effects of malaria in Kenya [20]. In children, the P1, the N2 and the P3a are the typical components observed in an auditory novelty oddball [21-23]. In a visual paradigm, the common components in children are the N1 [24], the P2 [25], the P3a [26] and the Nc [27,28] at midline electrodes and, if face stimuli are used, a facesensitive N170 at occipito-temporal sites [29]. Previous studies suggest that these ERP components may be clinically useful as an index of cognitive function [30]. We therefore recorded novelty processing in the auditory and visual modality and compared children with and without prior history of PM.

\section{Methods}

\section{Subjects}

Children with a history of PM were selected from the database of admissions to the paediatric ward at Kilifi District Hospital (KDH). PM was defined as cerebrospinal fluid culture (CSF), gram stain or latex antigen test positive for Streptococcus pneumonia. The children were resident in the Kilifi Demographic Surveillance System (DSS) to ensure that they could be identified in the community. At the time of assessment written consent was obtained from the parents/guardian. Exclusion criteria were presence of pre-existing congenital neurological conditions i.e. spina bifida, history of severe birth asphyxia or jaundice requiring medical intervention (phototherapy or exchange transfusion). Community controls were matched for sex and age (within 3 months), were residents in the Kilifi DSS for more than one year and had informed consent from parent/guardians. Those with a history of severe birth asphyxia, pre-existing neurological conditions and a history of neonatal jaundice were excluded. The study was approved by the National Ethics Committee.

There were 436 children admitted with PM at KDH during the period 1994-2004, of whom 113 (26\%) died in hospital (Figure 1). A sample size of 80 children was required to detect a difference between cases and controls with 90\% power and 95\% confidence interval [31]. To account for potential $15 \%$ failure-rate in recruitment, we generated a random list of 92 children who had been admitted to Kilifi District Hospital with PM from 1994 to 2004. Of those followed up 5 (5.4\%) had died after discharge, $9(9.2 \%)$ had migrated out of the study area and $12(13.2 \%)$ refused consent. Of the 66 who consented to the study, 1 child's ERP data was not analyzed due to excessive artefact. Sixty-five children (32 male; 33 female) aged between 4-15 years old (mean 8.4 yr, SD 3.1 yr) with a history of PM were included. A control group of 93 children (46 male; 47 female) aged between 4-15 years old (mean $8.4 \mathrm{yr}, \mathrm{SD} 2.6 \mathrm{yr}$ ) years was recruited from a well-demarcated study area in Kilifi from the DSS maintained in the KDH.

\section{Visual and auditory screening}

The visual and hearing screening was performed using the Sonksen-Silver [32] and Kamplex KS16 screening audiometer (P.C. Werth, UK) respectively. Auditory screening took place in a sound attenuated room to minimize environmental noise. Air conduction at 500 $\mathrm{Hz}, 1000 \mathrm{~Hz}, 2000 \mathrm{~Hz}$ and $4000 \mathrm{~Hz}$ in each ear was carried out according to the recommendations of British Society of Audiology (BSA, 1988). The hearing impairment was classified according to the lowest tone the ear could hear: mild impairment 26-40 dB, moderate impairment 41-60 dB, severe impairment 61-80 dB and profound impairment $>81 \mathrm{~dB}$.

Children with severe (unable to hear 61 - $80 \mathrm{~dB}$ on better ear) to profound (over $81 \mathrm{~dB}$ ) hearing impairment were excluded from the auditory paradigm analyses, resulting in seven children $(7.7 \%)$ being excluded from the PM group and none from the control group.

\section{ERP Recording}

Children who were 5 years-old or younger had electrodes individually positioned at the midline brain locations (i.e. $\mathrm{Fz}, \mathrm{FCz}, \mathrm{Cz}$ and $\mathrm{Pz}$ ) as well as A1, A2, HEOG, VEOG and Fpz using the international 10-20 system [33]. In the older children, a greater number of electrodes were used for recording including temporal sites (i. e. F7, F8, T3, T4, T5, T6, P3, and P4), frontal (i.e. Fp1 and Fp2) and mastoids (i.e. A1 and A2). All electrodes were referenced to $\mathrm{Cz}$ with $\mathrm{Fpz}$ as the ground electrode but re-referenced offline to linked mastoids.

The auditory paradigm was composed of three types of sounds: frequent and infrequent pure sinusoidal tones, and novel sounds. These tones and novel sounds were presented through two speakers placed in front of the children. Ten percent of the stimuli were infrequent tones $(2000 \mathrm{~Hz}, 200 \mathrm{~ms}$ long, $5 \mathrm{~ms}$ rise and fall time, 70 dB Sound Pressure Level, SPL), 10\% were composed of novel noises e.g. dog bark, bell ring, etc. whereas the remainder were frequent tones of $(1500 \mathrm{~Hz}, 200 \mathrm{~ms}$ long, $5 \mathrm{~ms}$ rise and fall time, $70 \mathrm{~dB}$ SPL). The duration of the tones/noises was 200 milliseconds (ms) with a stimulus onset asynchrony of $700 \mathrm{~ms}$. Two-blocks of 700 stimuli each were presented (560 frequent, 70 infrequent and 70 novels). Novel sounds were digitally adjusted in intensity so that they did not exceed $70 \mathrm{~dB}$ SPL as 


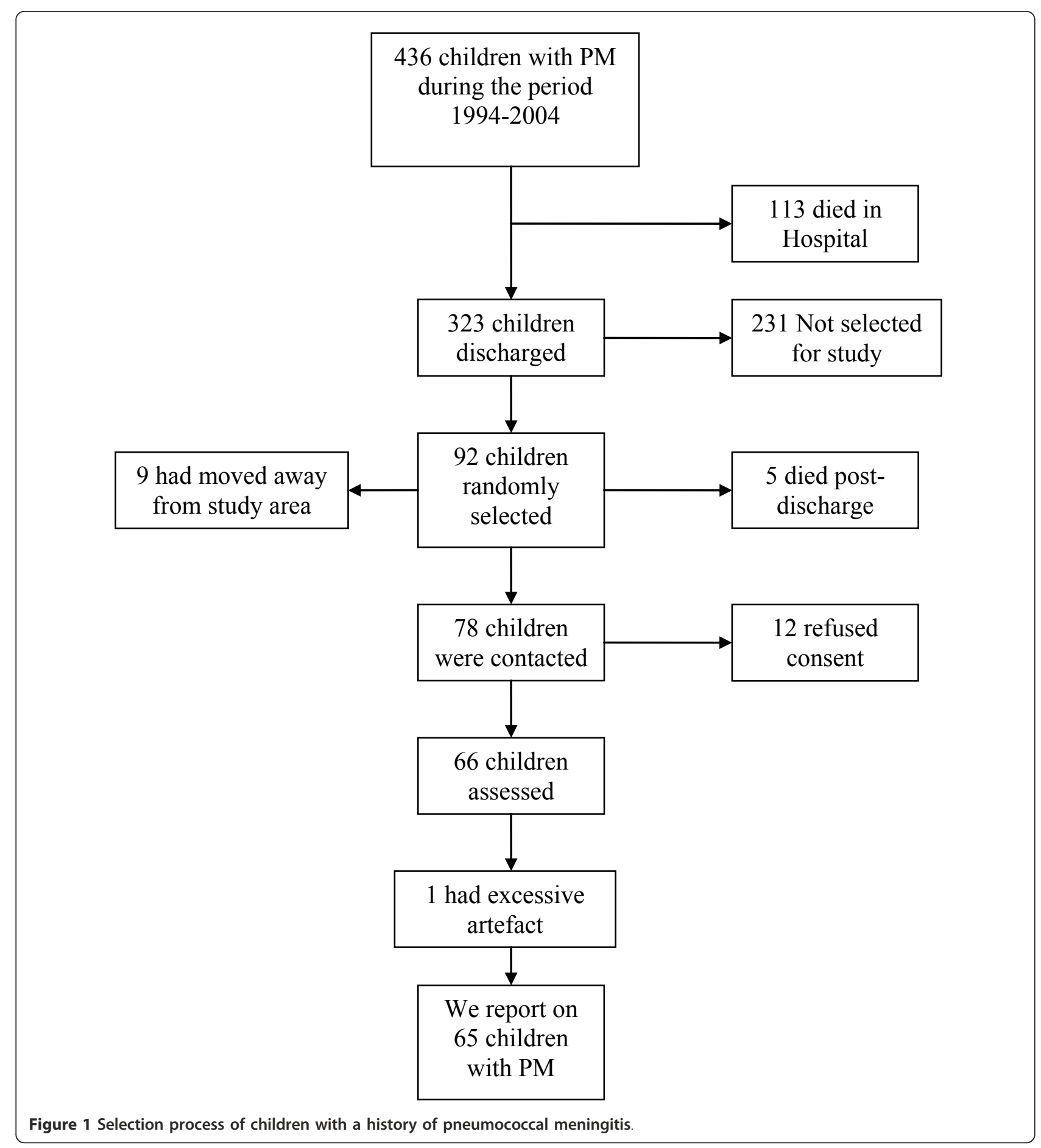

determined using a Bruel and Kjaer sound pressure meter. The frequent stimuli immediately prior to each infrequent stimulus were selected for averaging to provide similar signal-to-noise ratios.

The visual paradigm consisted of three kinds of images: an infrequently presented face and a frequently presented face (both were photographs of African women), and infrequently presented trial-unique, nonface abstract patterns (i.e. photographs of Kandinsky's paintings). Stimuli were of equal size and presented at a visual angle of $16.78 \times 14.25$ degrees. Two blocks of 100 trials were presented in a random order, with $60 \%$ of the trials showing the frequent face, $20 \%$ infrequent face, and $20 \%$ non-face abstract picture stimuli (trial 
unique). Participants were asked to look at a cross at the centre of the screen to minimize eye-movement artefacts. The duration of the image presentation was 500 $\mathrm{ms}$ with an inter-stimulus interval of $3000 \mathrm{~ms}$. In total, the tasks took between 20-30 minutes to complete.

Offline analyses of auditory data were collected using a $700 \mathrm{~ms}$ recording epoch with a $200 \mathrm{~ms}$ pre-stimulus baseline while the visual data had a 1500 ms recording epoch and a $200 \mathrm{~ms}$ baseline. EEG data were low-pass filtered offline at $20 \mathrm{~Hz}$ artefact-rejected (for blinks and muscle activity), baseline corrected, and waveforms were divided into epochs centred on stimulus presentation. An ocular artefact reduction algorithm on the Scan 4.3 software (Neuroscan ${ }^{\circledR}$ Labs) was used to remove artefacts due to blinking. Any trials with amplitude deflections exceeding $+/-100 \mu \mathrm{V}$ were rejected. A minimum of 20 trials for each stimulus was required for inclusion of an individual average ERP waveform.

In the auditory paradigm, the P1 component was defined as the highest peak between 60 and $130 \mathrm{~ms}$ post stimulus presentation and the N2 component was defined as the most negative point between 120 and 220 ms. The P3a component was defined as the most positive point occurring between 250 and $450 \mathrm{~ms}$.

In the visual paradigm, the N170 was defined as the most negative peak between $170-250 \mathrm{~ms}$ and was measured at occipito-temporal sites T5 and T6. The P3a was the highest peak between 270 and $450 \mathrm{~ms}$ and Nc was the average amplitude between 300 and $850 \mathrm{~ms}$.

All analysis was conducted using Predictive Analysis Software for Windows, version 18 (SPSS Inc ${ }^{\circledR}$, Chicago, USA). Within-subject factors included site (X4: Fz, FCz, $\mathrm{Cz}$ and $\mathrm{Pz}$ ) and stimuli (X3: frequent, infrequent and novel). The between-subject factors were age (X4: 4-5, $6-7,8-9,10-15)$ and sex (X2: male or female). The Greenhouse-Geisser correction is reported where applicable. We used the Tukey-Kramer test in the post-hoc analyses to correct for unequal sample sizes. Level of significance was set at $\mathrm{p}<0.05$.

\section{Results}

\section{Auditory ERPs}

Children with exposure to PM had consistently longer auditory ERP latencies (Figures 2 and 3), but comparable amplitudes with unexposed children except for the amplitude of the P1 component in younger children with PM. A more detailed comparison of the diagnostic groups on the various components is presented.

\section{Auditory P1}

Exposure to PM significantly affected the P1 latency [F $(1,176)=10.72, \mathrm{p}<0.015]$. This occurred due to longer mean P1 latency ( $99 \pm 22.5 \mathrm{~ms}$ vs $90 \pm 11.0 \mathrm{~ms})$ in children with exposure to PM compared to unexposed children [t $(190)=-2.991, p=0.003]$ (Figure 2). The amplitude for the P1 component had a main effect of diagnosis $[\mathrm{F}(1,176)=5.530, \mathrm{p}=0.020]$ and an interaction effect of electrode by diagnosis by age [F $(12,408)$ $=2.607, \mathrm{p}=0.014]$. The main effect occurred due to significantly smaller P1 amplitude in children exposed to PM compared to unexposed children (Figure 4). The interaction occurred due to significantly smaller amplitudes for the PM children at the Pz site for 4-5 and 6-7 year-olds $[3.3 \pm 2.7$ vs $1.24 \pm 2.2 \mu \mathrm{V}, \mathrm{p}=0.018$ and 4.5 \pm 3.2 vs $1.8 \pm 4.7 \mu \mathrm{V}, \mathrm{p}=0.047$ respectively].

\section{Auditory N2}

The N2 latency had significant interaction effect of stimulus by diagnosis by age $[\mathrm{F}(8,272)=2.560, \mathrm{p}=0.012]$. The interaction effect of stimulus by diagnosis by age occurred due to a significantly faster N2 latency for novel stimuli for unexposed children at age 10-15 years compared to younger ages [4-5 y $>10-15 \mathrm{y}, \mathrm{p}=0.021 ; 6-7 \mathrm{y}>$ $10-15$ y, $\mathrm{p}=0.019 ; 8-9 \mathrm{y}>10-15 \mathrm{y}, \mathrm{p}=0.024$ ] but not for children exposed to PM $[\mathrm{p}=0.248, \mathrm{p}=0.361$ and $\mathrm{p}=$ 0.803 respectively]. The $\mathrm{N} 2$ amplitude from baseline to peak did not differentiate between children with exposure to PM and unexposed children. However, the peak to peak amplitude (N2-P1) had main effects of age [F(4, $183)=14.011, \mathrm{p}<0.001]$ and diagnosis $[\mathrm{F}(1,183)=$ $10.445, \mathrm{p}=0.001]$. The main effect of age occurred due to decreasing amplitude differences with age. The main effect of diagnosis was due to significantly smaller amplitude differences for children exposed to PM compared to unexposed children (Figure 5).

\section{Auditory $\mathrm{P} 3 \mathrm{a}$}

The P3a latency had a significant main effect of diagnosis $[\mathrm{F}(1,136)=6.112, \mathrm{p}=0.015]$. This occurred due to longer P3a latency $(333 \pm 29.7 \mathrm{~ms}$ vs $321 \pm 15.1 \mathrm{~ms})$ in children with exposure to PM compared to unexposed children [t $(190)=-2.955, \mathrm{p}=0.004$ ] (Figure 3 ). The P3a amplitude both from baseline to peak and from peak to peak (P3a - N2) did not distinguish between the two diagnostic groups. There was no significant main effect of stimulus.

\section{Visual ERP}

Children with exposure to PM had a slightly different pattern of visual waveforms compared to unexposed children (Figure 6). The development of the ERPs by age that is evident in the waveforms of unexposed children was absent in children exposed to PM. The P3a component that occurs around $350 \mathrm{~ms}$ in controls was all but absent in the PM groups except in the older children (Figure 6), and the Nc component showed less differentiation among the visual stimuli in the unexposed compared to exposed group.

\section{Visual N170}

The latency and amplitude of the N170 component did not distinguish between PM and unexposed children. 


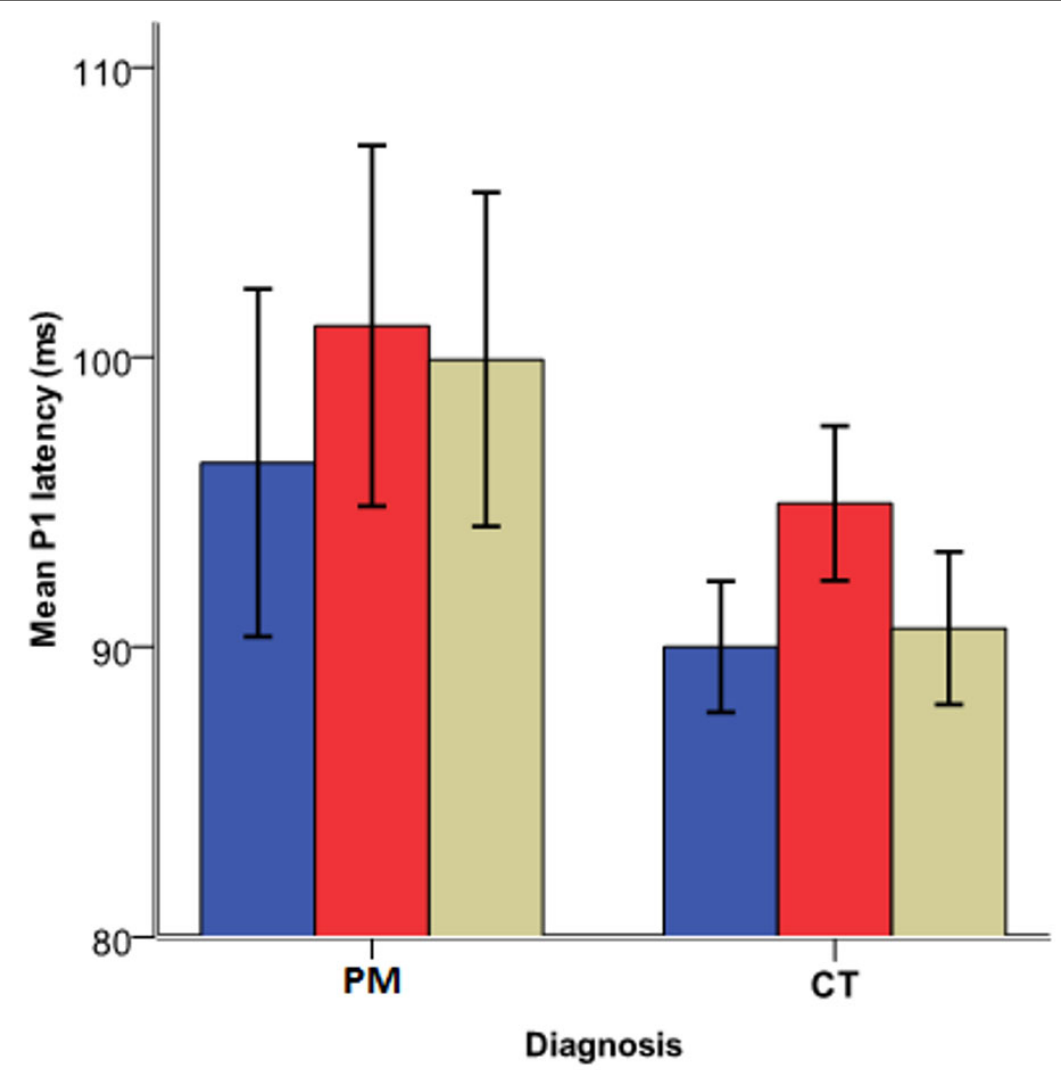

\section{$\square$ Novels Frequent Infrequent}

Error bars: $95 \% \mathrm{Cl}$

Figure 2 Auditory P1 latency for children with exposure to PM and controls.

\section{Visual P3a}

In the grand averaged waveforms of the children exposed to PM, there lacked a visual P3a component around 350-450 ms where it existed in the control group (Figure 5). In absence of the group averaged component, we did not study this component any further.

\section{Visual Nc}

The Nc revealed interaction effects of stimulus by diagnosis $[F(2,274)=3.952, p=0.026]$ and stimulus by electrode by diagnosis $[\mathrm{F}(6,822)=4.460, \mathrm{p}=0.004]$. The interaction of stimulus by diagnosis occurred due to larger amplitude associated with infrequent stimuli compared to frequent stimuli in unexposed children [2.7 \pm 5.4 vs $0.8 \pm 3.6 \mu \mathrm{V}, \mathrm{p}=0.001]$ but not in children with a history of PM [p $=0.386]$. The interaction of stimulus by electrode by diagnosis was due to larger amplitudes associated with infrequent compared to frequent stimuli at $\mathrm{Fz}, \mathrm{Cz}$ and $\mathrm{Pz}[\mathrm{p}=0.026, \mathrm{p}<0.001$ and $\mathrm{p}<0.001$ ] for unexposed children but not for children with a history of PM $[\mathrm{p}=0.479, \mathrm{p}=0.884$ and $\mathrm{p}=$ 0.136 respectively].

\section{Discussion}

The present study used auditory and visual event related potentials to novelty in children exposed pneumococcal meningitis, to investigate whether the disease disrupted the neural processes underlying visual and auditory attentional orienting, and its possible effects on brain processing as a marker of cognitive function [34].

Children exposed to PM had longer auditory P1 latencies than unexposed children. The P1 component has been thought to be an objective measure of cortical auditory function [35,36] or preferential attention [37] in children. In general, there are age-related decreases in P1 latency with increasing age, which is shown in children studies [38-40]. Longer P1 latencies in children with exposure to PM suggest slower or impaired development of their auditory functions. The P1 component is thought to be generated by the superior temporal gyrus [41]. The superior temporal gyrus contains several important structures of the brain, including those that deal with the sensation of sound and Wernicke's area (processing of speech). Previous studies show that children with a history of bacterial meningitis were at risk for language difficulties (post illness) $[5,42]$. The results may suggest that PM may result in a delayed processing perhaps due to subtle hearing loss resulting in longer P1 latencies in children with exposure to PM [36].

The auditory N2 latency is influenced by attention and task difficulty $[43,44]$. It is thought to reflect focused 


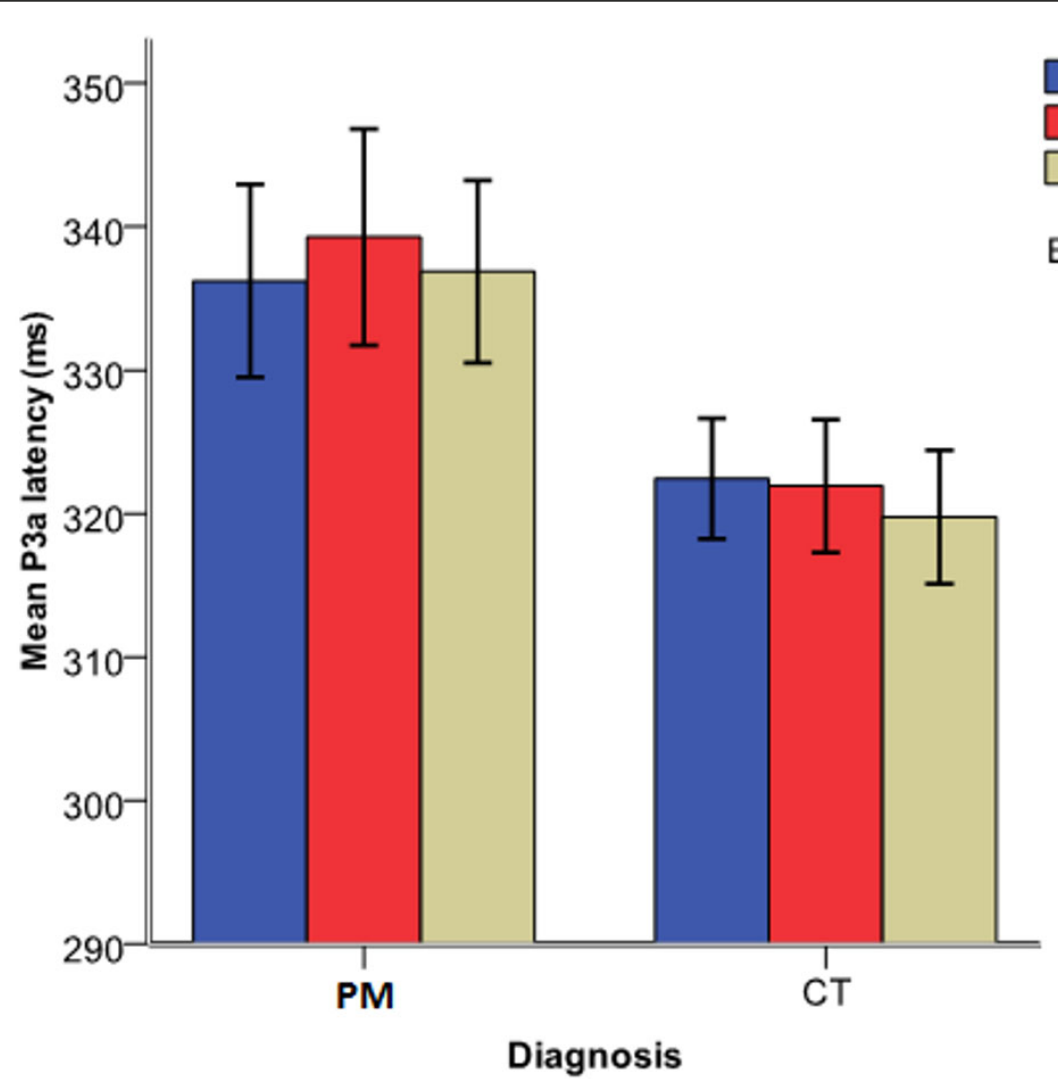

Figure 3 Comparison of mean P3a latency between children with exposure to PM and unexposed children.

attention to stimulus features [45] and is likely to index stimulus classification. Unexposed children showed decrease in the latency of the N2 component with age, but those exposed to PM had longer N2 latencies with age. The decrease of the N2 latency with age in unexposed children has been shown in previous studies [46-48]. This decrease is thought to represent maturational changes probably due to decreased synaptic density and an advance of intra-cortical myelination [38]. The N2 component is said to result from a deviation in form or context of a prevailing stimuli [49]. In the present study, novel sounds (environmental noises) provided a deviation from the standard tones $(1000 \mathrm{~Hz}, 70$ dB SPL) and target tones $(2000 \mathrm{~Hz}, 70 \mathrm{~dB}$ SPL) which acted as the prevailing stimuli. The auditory N2 is thought to originate bilaterally in the auditory cortex of the superior temporal lobes with frontal predominance [50]. It reflects attention orienting and its decrease with age may reflect inhibitory attention control [51].

The P1-N2 peak to peak amplitudes to novel stimuli showed significant differences between children with exposure to PM and unexposed community children. This aimed at determining whether the amplitude of the N2 component was influenced by the diagnosis of the children independent of the P1 component. The smaller brain responses in children with exposure to PM suggests deficits in cognitive processes necessary to discriminate novel stimuli [51,52].

The P3a component reflects an involuntary attention switch from the actual focus of voluntary attention to the eliciting sound [53], and is generated in the frontal lobes [54-56]. The P3a has also been interpreted as a neural correlate of the orienting response [57]. Our study results showed that children with exposure to pneumococcal meningitis had longer auditory P3a latencies compared to unexposed children. Studies have reported a decrease in P3a latencies with age [46,58-61] between 5 and 16 years but some have found no difference between 5 and12 years [62]. The results of the present study show that children with exposure to PM had much longer P3a latencies which can be attributed to impaired orientation to novelty, cognitive slowness or inflexible set-shifting. The P3a is recorded at the anterior locations and we speculate that PM does impair neural pathways in the frontal lobes, especially those dealing with executive functions [63].

The present study revealed absence of the visual P3a component in children exposed to PM. Some previous 


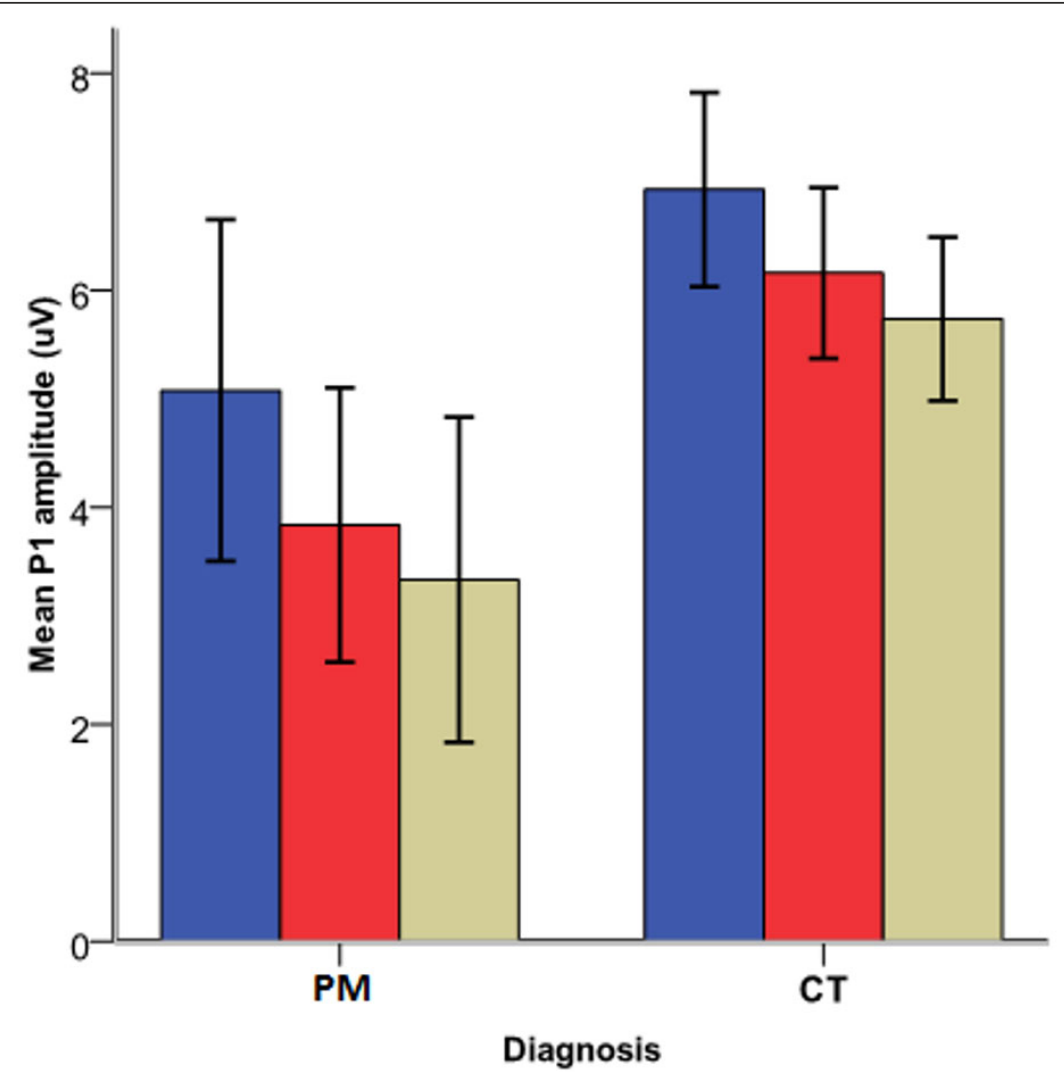

$\square$ Novels
$\square$ Frequent
$\square$ Infrequent

Error bars: $95 \% \mathrm{Cl}$

Figure 4 Auditory P1 amplitude for children with exposure to PM and controls.

studies have found marked reduction and even absence of this component in patients with alcoholism [44,64] and epilepsy patients [65]. The P3a component is thought to reflect automatic orienting and so its absence in children with exposure to PM is particularly interesting. Future studies should seek to study this component using an active paradigm.

Generally, amplitudes are related to the strength of the neural association while the latencies represent the time to respond to the stimuli [66]. The results of the latency differences suggest slowness or distractibility in children exposed to PM but not absence of response. Bacterial meningitis is thought to disrupt on-going brain maturation in developing children [5]. Frontal lobe development and myelination are critical and interruption of this process results in slowed information processing and poor development of executive functioning $[67,68]$.

Previous research has reported potentially serious cognitive consequences in children with a history of pneumococcal meningitis $[6,12,42]$. These children have lower IQ's and performed poorer on neuropsychological tests than their peers many years post infection. Damage to frontal lobes leads to diminished attention through disruption of neural process $[69,70]$. The results of the present study thus suggest that pneumococcal meningitis impairs neural development in the frontal lobes, causing negative effects on children's cognitive development in general and affecting their academic outcomes.

\section{Limitation of the study}

The results of the auditory paradigm of study should be interpreted with caution since bacterial meningitis is known to cause subtle to profound hearing loss and the children were not fitted with hearing aids. Children with severe to profound hearing loss were excluded from the ERP paradigms to minimize obvious biases arising from sensory impairments. However, it is possible that subtle hearing loss and cortical blindness could have accounted for the differences in children with pneumococcal meningitis. The auditory N2 and visual P2 latencies are indices of processing speed and attention allocation and could have been affected by subtle impairments.

Also, a lack of neuropsychological testing in this study meant that we could not compare the differences in function between children exposed to PM and those who were unexposed.

Studies in Africa have shown a high HIV prevalence in children with meningitis [71]. However, the children in the present study did not have their HIV status 


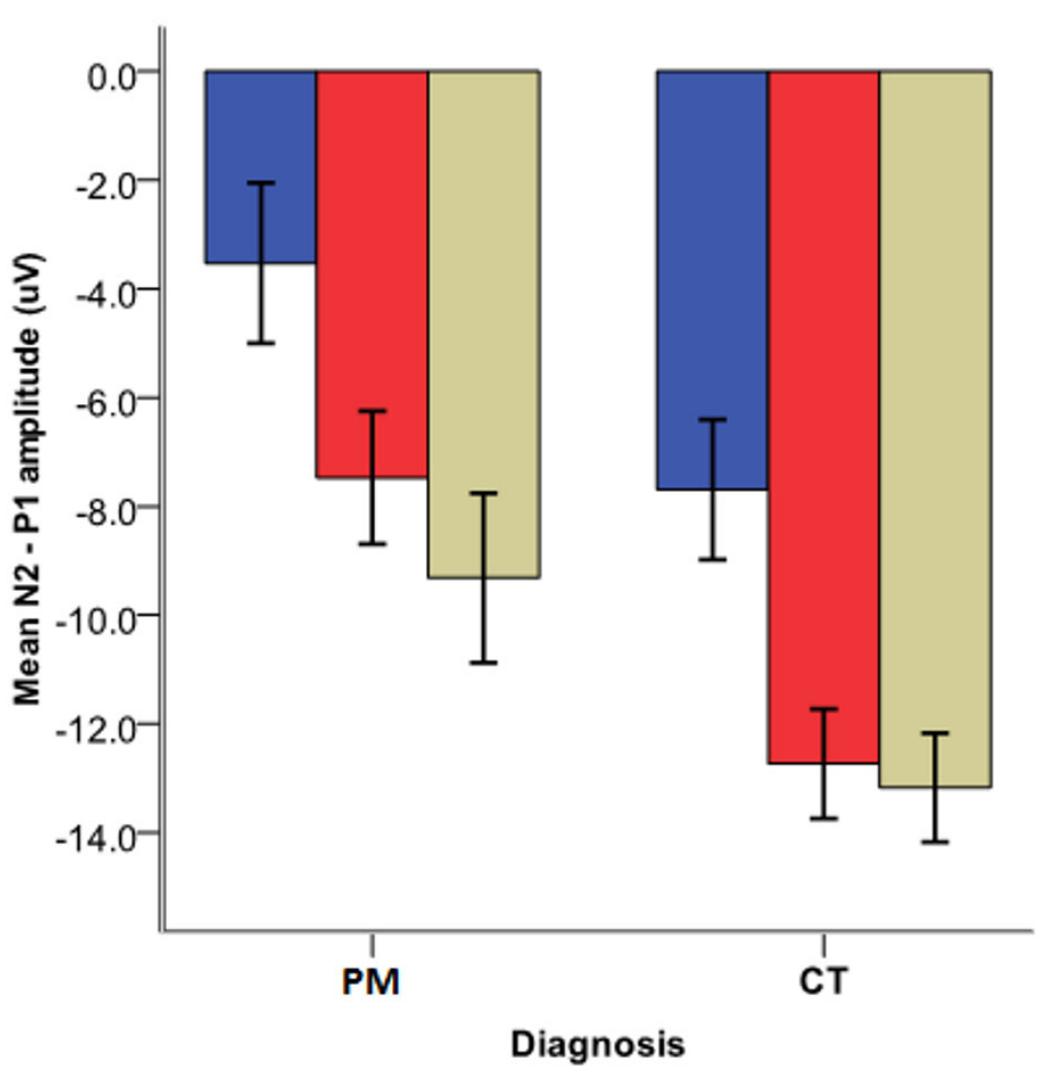

\section{Novels \\ $\square$ Frequent $\square$ Infrequent}

Error bars: $95 \% \mathrm{Cl}$

Figure 5 Mean auditory N2-P1 amplitude for children with exposure to PM and controls.

investigated and their sero-status may have influenced the study results.

\section{Conclusion}

The results of the passive ERP paradigm show that there is a difference between children exposed to pneumococcal meningitis and unexposed children. These exposed children generally have a slower brain processing as depicted by their longer ERP latencies of the various components. The results suggest impaired development of frontal cortex and/or its connecting pathways, possibly due to disruption of brain development by meningitis infection. This methodology may be useful for assessment of the development of perceptual-cognitive functions in African children providing an alternate way of assessing perceptual-cognitive development in patient

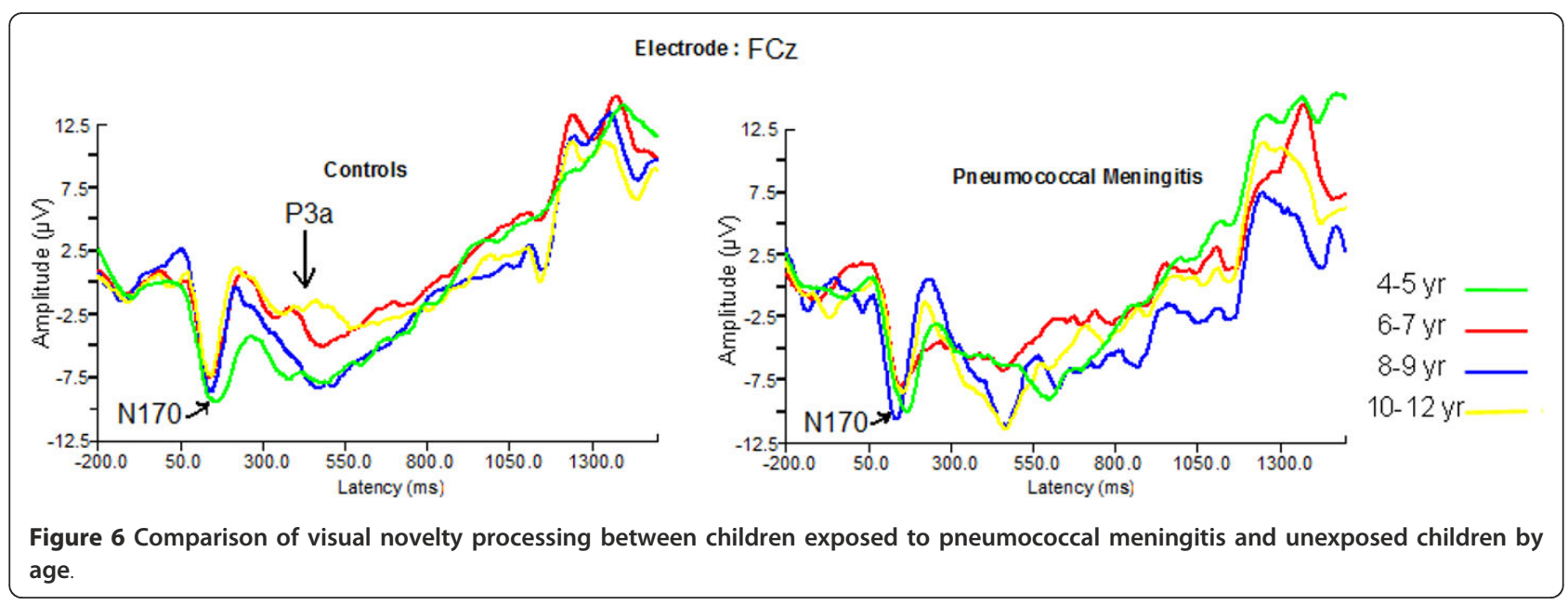




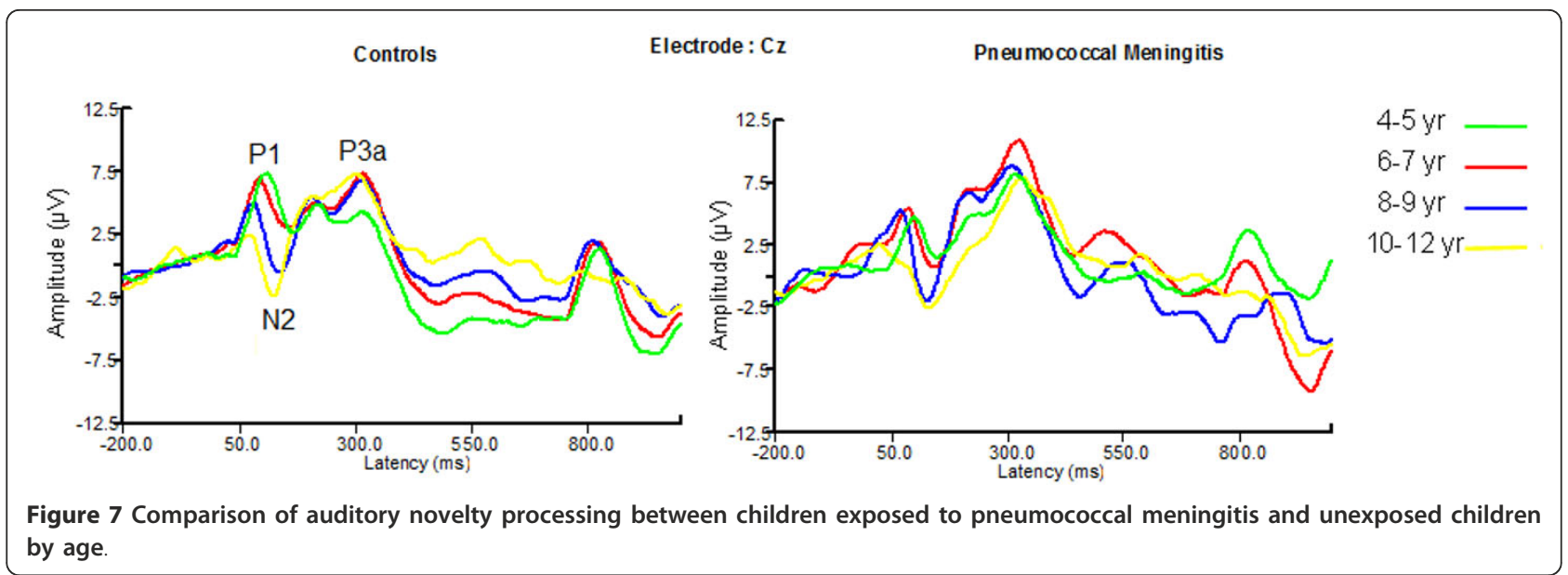

groups for whom more typical standardized neuropsychological assessments are unavailable.

\section{Acknowledgements}

This study was funded by the Wellcome Trust [Prof Charles Newton (070114) as part of a Senior Clinical Fellowship and Strategic Award (084538)]. Apart from funding, the Trust has had no role in the conduct of the study, data analysis or the decision to submit the manuscript. The study is published with the permission of the Director of KEMRI. The authors would also wish to thank Judy Tumaini for assisting in visual and auditory testing, Joshua Gandi for data entry and Francis Yaah for recruiting patients. We also wish to sincerely thank all children and their parents/guardians for consenting to take part in this study.

\section{Author details}

'The Centre for Geographical Medicine Research (Coast), Kenya Medical Research Institute, Kilifi, Kenya. ${ }^{2}$ Developmental Cognitive Neuroscience Unit, University College London Institute of Child Health, London, UK.

${ }^{3}$ Department of Paediatrics, University of Nairobi, Kenyatta National Hospital, Nairobi, Kenya. ${ }^{4}$ Neurosciences Unit, University College London Institute of Child Health, The Wolfson Centre, London, UK. ${ }^{5}$ London School of Hygiene and Tropical Medicine (LSHTM), London, UK.

\section{Authors' contributions}

MK, EOW, BGRN and CRJCN were responsible for the conception of the study, its design, data collection and critical review of the manuscript. HH and MK were involved in the recording and analysis of the event-related potentials. MdH, CRJCN and MK were involved in the evaluation and interpretation of results. MK wrote the initial draft of the manuscript and all other authors contributed substantially to the content. All authors have read and approved the final manuscript

\section{Competing interests}

The authors declare that they have no competing interests.

Received: 25 February 2011 Accepted: 31 March 2012

Published: 31 March 2012

\section{References}

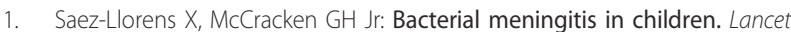
2003, 361:2139-2148

2. Boisier P, Mainassara HB, Sidikou F, Diibo S, Kairo KK, Chanteau S: Casefatality ratio of bacterial meningitis in the African meningitis belt: we can do better. Vaccine 2007, 25(Suppl 1):A24-A29.

3. Molyneux E, Riordan FA, Walsh A: Acute bacterial meningitis in children presenting to the Royal Liverpool Children's Hospital, Liverpool, UK and the Queen Elizabeth Central Hospital in Blantyre, Malawi: a world of difference. Ann Trop Paediatr 2006, 26:29-37.
4. Anderson V, Anderson P, Grimwood K, Nolan T: Cognitive and executive function 12 years after childhood bacterial meningitis: effect of acute neurologic complications and age of onset. J Pediatr Psychol 2004, 29:67-81.

5. Anderson V, Bond L, Catroppa C, Grimwood K, Keir E, Nolan T: Childhood bacterial meningitis: impact of age at illness and acute medical complications on long term outcome. J Int Neuropsychol Soc 1997, 3:147-158.

6. Grimwood K, Anderson P, Anderson V, Tan L, Nolan T: Twelve year outcomes following bacterial meningitis: further evidence for persisting effects. Arch Dis Child 2000, 83:111-116.

7. Chandran A, Herbert H, Misurski D, Santosham M: Long-term Sequelae of Childhood Bacterial Meningitis: An Underappreciated Problem. J Pediatr Infect Dis 2010, 30(1):3-6.

8. Ramakrishnan M, Ulland AJ, Steinhardt LC, Moisi JC, Were F, Levine OS: Sequelae due to bacterial meningitis among African children: a systematic literature review. BMC Med 2009, 7:47.

9. Christie D, Viner RM, Knox K, Coen PG, Wang H, El Bashir H, Legood R, Patel BC, Booy R: Long-term outcomes of pneumococcal meningitis in childhood and adolescence. Eur J Pediatr 2011, 170:997-1006.

10. Bedford H, de Louvois J, Halket S, Peckham C, Hurley R, Harvey D: Meningitis in infancy in England and Wales: follow up at age 5 years. BMJ 2001, 323:533-536.

11. Merkelbach S, Sittinger $\mathrm{H}$, Schweizer I, Muller M: Cognitive outcome after bacterial meningitis. Acta Neurol Scand 2000, 102:118-123.

12. Schmidt H, Heimann B, Djukic M, Mazurek C, Fels C, Wallesch CW, Nau R: Neuropsychological sequelae of bacterial and viral meningitis. Brain 2006, 129:333-345

13. Schmand B, de Bruin E, de Gans J, van de Beek D: Cognitive functioning and quality of life nine years after bacterial meningitis. J Infect 2010, 61:330-334.

14. Sparrow SS, Davis SM: Recent advances in the assessment of intelligence and cognition. J Child Psychol Psychiatry 2000, 41:117-131.

15. Holding PA, Kitsao-Wekulo PK: Describing the burden of malaria on child development: what should we be measuring and how should we be measuring it? Am J Trop Med Hyg 2004, 71:71-79.

16. Foxcroft CD: Ethical Issues Related to Psychological Testing in Africa: What I have learned (so far). Book Ethical Issues Related to Psychological Testing in Africa: What I have learned (so far) Port Elizabeth 2011 [http:// scholarworks.gvsu.edu/orpc/vol2/iss2/7]

17. Robertson K, Liner J, Heaton R: Neuropsychological assessment of HIVinfected populations in international settings. Neuropsychol Rev 2009, 19:232-249.

18. Pfefferbaum A, Roth WT, Ford JM: Event-related potentials in the study of psychiatric disorders. Arch Gen Psychiatry 1995, 52:559-563.

19. Sokhadze E, Baruth J, Tasman A, Sears L, Mathai G, El-Baz A, Casanova MF: Event-related potential study of novelty processing abnormalities in autism. Appl Psychophysiol Biofeedback 2009, 34:37-51. 
20. Kihara M, de Haan M, Garrashi HH, Neville BR, Newton CR: Atypical brain responses to novelty in rural African children with a history of severe falciparum malaria. J Neurol Sci 2010, 296:88-95.

21. Lepisto T, Kujala T, Vanhala R, Alku P, Huotilainen M, Naatanen R: The discrimination of and orienting to speech and non-speech sounds in children with autism. Brain Res 2005, 1066:147-157.

22. Mikkola K, Kushnerenko E, Partanen E, Serenius-Sirve S, Leipala J, Huotilainen M, Fellman V: Auditory event-related potentials and cognitive function of preterm children at five years of age. Clin Neurophysiol 2007, 118:1494-1502.

23. Whitehouse AJ, Bishop DV: Do children with autism 'switch off' to speech sounds? An investigation using event-related potentials. Dev Sci 2008, 11:516-524.

24. Rossion B, Campanella S, Gomez CM, Delinte A, Debatisse D, Liard L, Dubois $S$, Bruyer $R$, Crommelinck M, Guerit JM: Task modulation of brain activity related to familiar and unfamiliar face processing: an ERP study. Clin Neurophysiol 1999, 110:449-462.

25. Heslenfeld DJ, Kenemans JL, Kok A, Molenaar PC: Feature processing and attention in the human visual system: an overview. Biol Psychol 1997, 45:183-215.

26. Gumenyuk V: Electrophysiological and Behavioral Indices of Distractibility in School-age Children. Ph.D Thesis. University of Helsinki, Psychology; 2005.

27. Courchesne E, Hillyard SA, Galambos R: Stimulus Novelty, Task Relevance and the Visual Evoked Potential in Man. Electroencephalogr Clin Neurophysiol 1975, 39:131-143.

28. Thomas KM, Nelson CA: Age-related changes in the electrophysiological response to visual stimulus novelty: a topographical approach. Electroencephalogr Clin Neurophysiol 1996, 98:294-308.

29. Bentin S, Allison T, Puce A, Perez E, McCarthy G: Electrophysiological studies of face perception in humans. J Cogn Neurosci 1996, 8:551-565.

30. Picton TW, Bentin S, Berg P, Donchin E, Hillyard SA, Johnson R, Miller GA, Ritter W, Ruchkin DS, Rugg MD, Taylor MJ: Guidelines for Using Human Event-Related Potentials to Study Cognition: Recording Standards and Publication Criteria. Psychophysiology 2000, 37:127-152

31. Were E: Survival and long-term neuro-developmental outcome of children admitted to a Kenyan District Hospital with Pneumococcal Meningitis. MMed (Pediatrics). Thesis University of Nairobi, Kenya; 2007.

32. Salt AT, Sonken PM, Wade A, Jayatunga R: The Maturation of Linear acuity and compliance with the Sonksen-Silver Acuity System for young children. Dev Med Child Neurol 1995, 37:505-514.

33. Jasper $\mathrm{HH}$ : The $10-20$ electrode system of the international federation. Electroencephalogr Clin Neurophysiol 1958, 10:370-375.

34. Carter CS, Barch DM: Imaging biomarkers for treatment development for impaired cognition: report of the sixth CNTRICS meeting: Biomarkers recommended for further development. Schizophr Bull 2012, 38:26-33.

35. Naatanen R, Picton $\mathrm{T}$ : The $\mathrm{N} 1$ wave of the human electric and magnetic response to sound: a review and an analysis of the component structure. Psychophysiology 1987, 24:375-425.

36. Sharma A, Martin K, Roland P, Bauer P, Sweeney MH, Gilley P, Dorman M: P1 latency as a biomarker for central auditory development in children with hearing impairment. J Am Acad Audiol 2005, 16:564-573.

37. Key APF, Dove GO, Maguire MJ: Linking Brainwaves to the Brain: An ERP Primer. Dev Neuropsychol 2005, 27:183-215.

38. Ceponiene R, Rinne T, Naatanen R: Maturation of cortical sound processing as indexed by event-related potentials. Clin Neurophysiol 2002, 113:870-882

39. Ponton CW, Eggermont JJ, Don M, Waring MD, Kwong B, Cunningham J, Trautwein P: Maturation of the mismatch negativity: effects of profound deafness and cochlear implant use. Audiol Neurootol 2000, 5:167-185.

40. Sharma A, Kraus N, McGee TJ, Nicol TG: Developmental changes in P1 and $\mathrm{N} 1$ central auditory responses elicited by consonant-vowel syllables. Electroencephalogr Clin Neurophysiol 1997, 104:540-545.

41. Thoma RJ, Hanlon FM, Moses SN, Edgar JC, Huang M, Weisend MP, Irwin J, Sherwood A, Paulson K, Bustillo J, et al: Lateralization of auditory sensory gating and neuropsychological dysfunction in schizophrenia. Am J Psychiatry 2003, 160:1595-1605.

42. Pentland LM, Anderson VA, Wrennall JA: The implications of childhood bacterial meningitis for language development. Child Neuropsychol 2000, 6:87-100.
43. Naatanen R: Attention and Brain function Hilsdale, New Jersey: Lawrence Erlbaum; 1992

44. Patel SH, Azzam PN: Characterization of N200 and P300: selected studies of the Event-Related Potential. Int J Med Sci 2005, 2:147-154

45. Breton F, Ritter W, Simson R, Vaughan HG Jr: The N2 component elicited by stimulus matches and multiple targets. Biol Psychol 1988, 27:23-44.

46. Courchesne E: Neurophysiological correlates of cognitive development: changes in long-latency event-related potentials from childhood to adulthood. Electroencephalogr Clin Neurophysiol 1978, 45:468-482.

47. Enoki H, Sanada S, Yoshinaga H, Oka E, Ohtahara S: The effects of age on the N200 component of the auditory event-related potentials. Brain Res Cogn Brain Res 1993, 1:161-167.

48. Goodin DS, Squires KC, Henderson BH, Starr A: Age-related variations in evoked potentials to auditory stimuli in normal human subjects. Electroencephalogr Clin Neurophysiol 1978, 44:447-458.

49. Naatanen R, Picton TW: N2 and automatic versus controlled processes. Electroencephalogr Clin Neurophysiol Suppl 1986, 38:169-186.

50. Gomot M, Giard MH, Roux S, Barthelemy C, Bruneau N: Maturation of frontal and temporal components of mismatch negativity (MMN) in children. Neuroreport 2000, 11:3109-3112.

51. Satterfield JH, Schell AM, Nicholas T: Preferential neural processing of attended stimuli in attention-deficit hyperactivity disorder and normal boys. Psychophysiology 1994, 31:1-10.

52. Papaliagkas VT, Kimiskidis VK, Tsolaki MN, Anogianakis G: Cognitive eventrelated potentials: longitudinal changes in mild cognitive impairment. Clin Neurophysiol 2011, 122:1322-1326.

53. Knight RT, Scabini D: Anatomic Bases of Event-Related Potentials and Their Relationship to Novelty Detection in Humans. J Clin Neurophysiol 1998, 15:3-13.

54. Friedman D, Simpson G, Hamberger M: Age-related changes in scalp topography to novel and target stimuli. Psychophysiology 1993, 30:383-396.

55. Friedman D, Simpson GV: ERP amplitude and scalp distribution to target and novel events: effects of temporal order in young, middle-aged and older adults. Brain Res Cogn Brain Res 1994, 2:49-63.

56. Knight RT: Decreased response to novel stimuli after prefrontal lesions in man. Electroencephalogr Clin Neurophysiol 1984, 59:9-20.

57. Soltani M, Knight RT: Neural Origins of the P300. Neurobiology 2000, 14:199-224.

58. Cycowicz YM, Friedman D, Rothstein M: An ERP developmental study of repetition priming by auditory novel stimuli. Psychophysiology 1996, 33:680-690.

59. Gumenyuk V, Korzyukov O, Alho K, Escera C, Naatanen R: Effects of auditory distraction on electrophysiological brain activity and performance in children aged 8-13 years. Psychophysiology 2004, 41:30-36.

60. Gumenyuk V, Korzyukov O, Alho K, Escera C, Schroger E, Ilmoniemi RJ, Naatanen R: Brain activity index of distractibility in normal school-age children. Neurosci Lett 2001, 314:147-150.

61. Fuchigami T, Okubo O, Ejiri K, Fujita Y, Kohari R, Noguchi Y, Fuchigami S, Hiyoshi K, Nishimura A, Harada K: Developmental Changes in P300 Wave Elicited During Two Different Experimental Conditions. Pediatr Neurol 1995, 13:25-28

62. Brinkman MJ, Stauder JE: The development of passive auditory novelty processing. Int I Psychophysiol 2008, 70:33-39.

63. Fjell $A M$, Rosquist $H$, Walhovd KB: Instability in the latency of P3a/P3b brain potentials and cognitive function in aging. Neurobiol Aging 2009, 30:2065-2079.

64. Olbrich HM, Maes H, Gann H, Hagenbuch F, Feige B: Auditory and visual event-related potentials in alcoholics: abnormalities of components and brain electrical field. Eur Arch Psychiatry Clin Neurosci 2000, 250:215-220.

65. Duncan CC, Mirsky AF, Lovelace CT, Theodore WH: Assessment of the attention impairment in absence epilepsy: comparison of visual and auditory P300. Int J Psychophysiol 2009, 73:118-122.

66. Polich J, Alexander JE, Bauer LO, Kuperman S, Morzorati S, O'Connor SJ, Porjesz B, Rohrbaugh J, Begleiter H: P300 topography of amplitude/ latency correlations. Brain Topogr 1997, 9:275-282.

67. Anderson V, Moore C: Age at Injury as a Predictor of Outcome Following Pediatric Head Injury: A longitudinal perspective. Child Neuropsychol 1995, 2:187-202. 
68. Wrightson P, McGinn V, Gronwall D: Mild head injury in preschool children: evidence that it can be associated with a persisting cognitive defect. J Neurol Neurosurg Psychiatry 1995, 59:375-380.

69. Daffner KR, Mesulam MM, Scinto LF, Acar D, Calvo V, Faust R, Chabrerie A, Kennedy B, Holcomb P: The central role of the prefrontal cortex in directing attention to novel events. Brain 2000, 123(Pt 5):927-939.

70. Snyder JJ, Chatterjee A: The frontal cortex and exogenous attentional orienting. J Cogn Neurosci 2006, 18:1913-1923.

71. McCormick DW, Molyneux EM: Bacterial Meningitis and Haemophilus influenzae Type b Conjugate Vaccine, Malawi. Emerg Infect Dis 2011, 17:688-690.

Pre-publication history

The pre-publication history for this paper can be accessed here: http://www.biomedcentral.com/1471-2334/12/79/prepub

doi:10.1186/1471-2334-12-79

Cite this article as: Kihara et al:: Cognitive deficits following exposure to pneumococcal meningitis: an event-related potential study. BMC

Infectious Diseases 2012 12:79.

\section{Submit your next manuscript to BioMed Central} and take full advantage of:

- Convenient online submission

- Thorough peer review

- No space constraints or color figure charges

- Immediate publication on acceptance

- Inclusion in PubMed, CAS, Scopus and Google Scholar

- Research which is freely available for redistribution

Submit your manuscript at www.biomedcentral.com/submit 